\title{
Directions of wage optimization in construction
}

\author{
I.V. Yamshchikova ${ }^{1, *}, T . G$. Doroshenko ${ }^{2}$, and N.B. Mikheeva ${ }^{3}$ \\ ${ }^{1}$ EDP Sciences, Department of real estate expertise and management, Irkutsk National Research \\ Technical University, Lermontov Street 83, 664038 Irkutsk, Russia \\ ${ }^{2}$ Second affiliation, Department of construction economy and property management, Baikal State \\ University, 11 Lenin St., 664003, Irkutsk, Russian \\ ${ }^{3}$ Krasnoyarsk State Agrarian University, 90 Mira Ave., 660049, Krasnoyarsk, Russia
}

\begin{abstract}
The article analyses the method proposed by the Government of the Russian Federation for adjusting the principle of determining the minimum subsistence level, based on the median salary. The article shows the result of the analysis of changes in wages in construction when calculating, using the median salary in relation to the "absolute" principle of calculating the minimum subsistence level, the calculation of the size of the minimum subsistence level in Russia as a whole, and on the territory of the Irkutsk region is analysed. It is shown that the transition to the calculation of the median salary in the Irkutsk region will decrease the subsistence level in relation to the existing one. Based on our analysis, the conclusion is made that in order to calculate the minimum subsistence level for medial salary, it is necessary to revise the calculation methodology.
\end{abstract}

\section{Introduction}

Currently, the size of the planned and actual funds for a wage in construction directly depends on the value of the subsistence level (SL) in the region. Currently, the size of the SL is determined based on the composition of the minimum consumer basket introduced in 1997 by Federal Law No. 134-FZ. Due to the fact that the composition of the consumer basket has existed with minor adjustments for 23 years, the need has matured to optimize the methodological approach to its determination [1]. The current composition of the minimum consumer basket was fixed in 2012 by Federal Law No. 227-FZ and consists of three sections:

1. Food products;

2. Non-food products;

3. Services.

The non-food part of the SL is tied to the food part, it is believed that the minimum nonfood consumption should cost $50 \%$ of the food basket; the same is applied for the services. Further, compulsory payments and fees are added to the subsistence level. This "natural" basket should be revised every five years, the last time it was supposed to happen in 2018 ,

\footnotetext{
* Corresponding author: yamsirina@yandex.ru
} 
but due to a significant increase in the minimum wage and bringing it to the level of the subsistence level, the revision was postponed until the end of 2020.

In 2020, the Russian government approved a bill to change the minimum wage and subsistence level starting from 2021. The size of the restrictions will be compared with the median salary, as a result of which, according to the Russian government, salaries are expected to increase in all industries.

\section{Materials and methods}

The information base of the scientific research was made up of the data from the accounting (financial) statements of construction organizations in the city of Irkutsk, as well as materials submitted by the Statistics Service of Irkutsk (irkutskstat.old.gks.ru) in the "Construction" field

The methodological basis of the study is made up of methods of economic and statistical analysis, a systemic method, systematization of theoretical and practical material.

The analysis and optimization of funds for wages as part of the cost of construction products is based on the methodology for determining the cost of construction products in the territory of the Russian Federation, which is relevant for the study period.

\section{Results}

The current model of the social level of consumption and the procedure for determining the level of poverty of the population was inherited from the USSR and represents the first model, the "absolute" one [2]. Following such a model, the poor are those who do not have the income to consume the minimum basket of goods and services. In most EU and OECD countries, a "relative" approach is used, according to which the poverty line is determined in relation to the "standard", usual consumption accepted in society.

The value of the minimum subsistence level is directly related to the methodology for determining funds for wages in construction [3-6]. Payroll planning in accordance with the Methodology for Determining the Cost of Construction Products (MDS81-35.2004) is based on the indicator of the cost of a man-hour for each skill category. The cost of an hour, in turn, is determined based on the minimum subsistence level

Our analysis of the funds planned for wages as part of the estimate documentation and the amount of salary stipulated by the "Federal Sectoral Agreement on the Construction and Industry of Building Materials of the Russian Federation", concluded for 2017-2020, which came into force on January 1, 2017 and is valid until December 31, 2020 [7-8], shows an underestimation of the planned salary. (Fig.1).

As can be seen from Fig. 1, in the first quarter of 2015, the cost presented in the collection "Price Indices in Construction" (the Irkutsk region) is underestimated in relation to the Sectoral Rate Agreement, which was not observed over the period under review, such a negative deviation is observed up to Q2 2019, i.e., over 4 years. The maximum deviation reached 20.5\% in Q2 2016. Currently, there is a tendency towards an increase in the cost of a man-hour in relation to the Industry Agreement, however, this excess is gradually decreasing, and according to the forecast determined along the trend line, by the end of 2021 it will become negative again. 


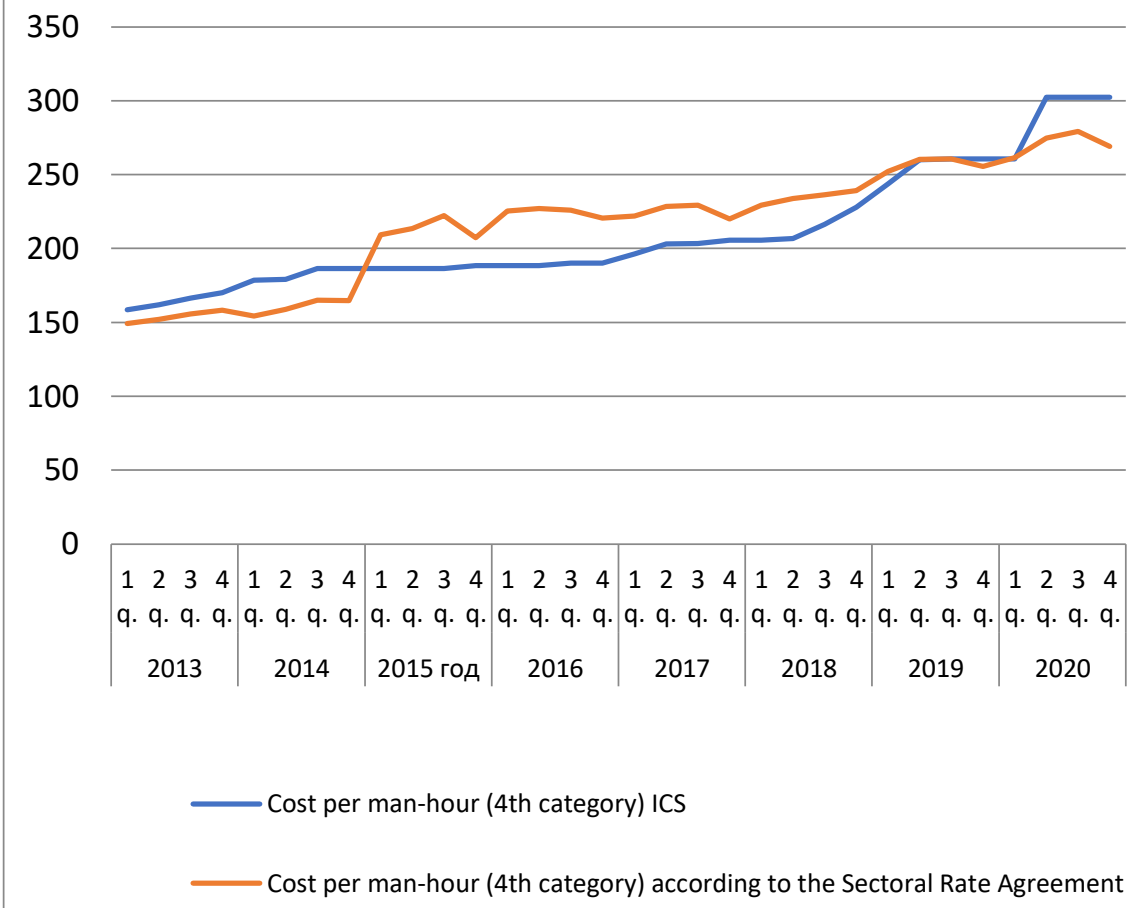

Fig. 1. Comparative change in the cost of man-hour under the Sectoral Rate Agreement and the actual value presented in the Information Bulletin (Irkutsk Region)

Based on the foregoing, it can be concluded that there is an urgent need to correct the principle of establishing a subsistence level and the minimum wage. The Russian government proposes to abandon the calculation of the subsistence level as the statistical cost of the consumption basket from 2021, and define the same as a part (44.2\%) of the average per capita income. The Ministry of Labor proposes to set the minimum wage until 2026 at the level of $42 \%$ of the median salary.

\section{Discussion}

Currently, the Federal State Statistics Service has begun experimental calculations of the median salary, on the indicator of which the subsistence level will depend from 2021. Until now, the Federal State Statistics Service made the said calculations only once every two years and only for a sample of employees of large and medium-sized enterprises; the last such calculation was made according to the data for April 2019 and amounted to RUB 34,335 . It is currently possible to calculate the median salary only according to data on insurance contributions to the Pension Fund, the amount of which directly depends on the actually paid salary, i.e., it is not correct $[9,10]$. Furthermore, calculations show that the value of the median salary fluctuates depending on the region, and in the Irkutsk region it is less than the average for Russia in April 2019 by $23.4 \%$, and in 2020 and by $40.9 \%$ in 2021. (Fig.2). 


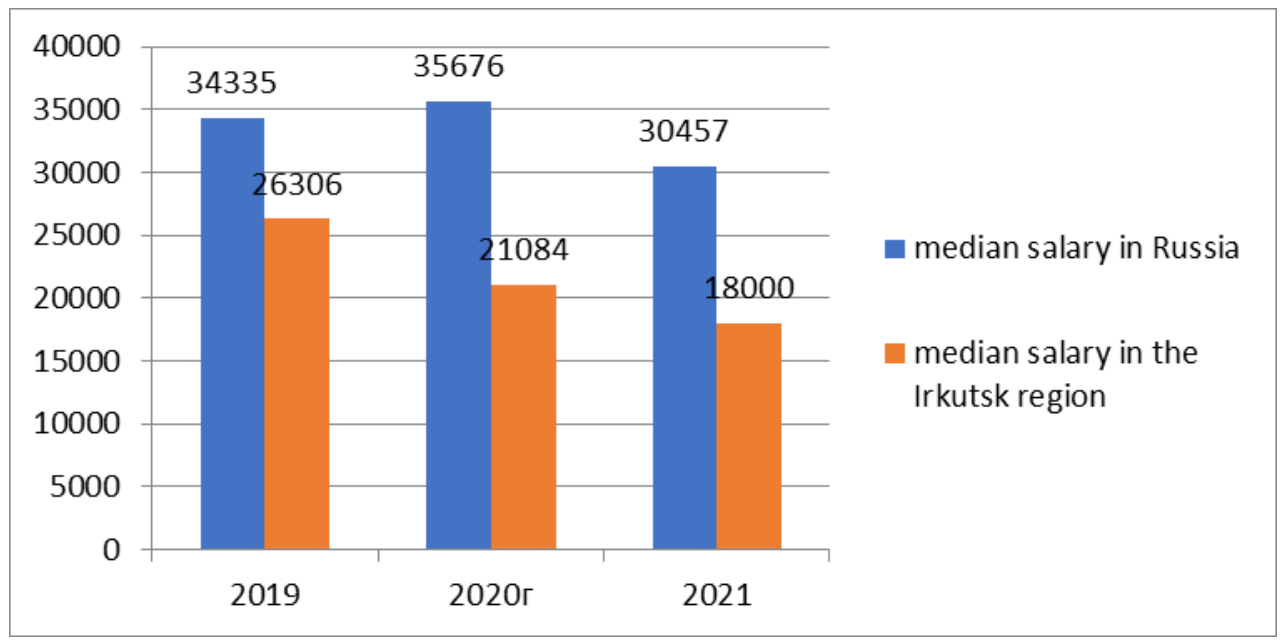

Fig. 2. Comparative change in median salary on average across Russia and the Irkutsk region

Figure 2 shows that in 2020, the median salary in Russia grew by $3.9 \%$ on average, i.e., in proportion with the inflation rate, and in the Irkutsk region there was a $20 \%$ decrease.

To calculate the subsistence level, it is proposed to take the share of the median income for the country and fix it at $44.2 \%$ for the next five years; for the working population, it is proposed to introduce an increasing coefficient of 1.09. The size of the subsistence level using the median salary and using the consumer basket in Russia as a whole and in the Irkutsk region was analysed. (Fig.3). As can be seen from Figure 3, the subsistence level for the Irkutsk region, according to the calculations of the level of 2019 alone, exceeds the SL in the consumer basket by $5.8 \%$. At the level of calculation for 2020, the SL currently established for the consumer basket exceeds the proposed "median" by $22 \%$, and at the estimated level of 2021, which will be proposed for use, the deviation will already increase to almost $50 \%$.

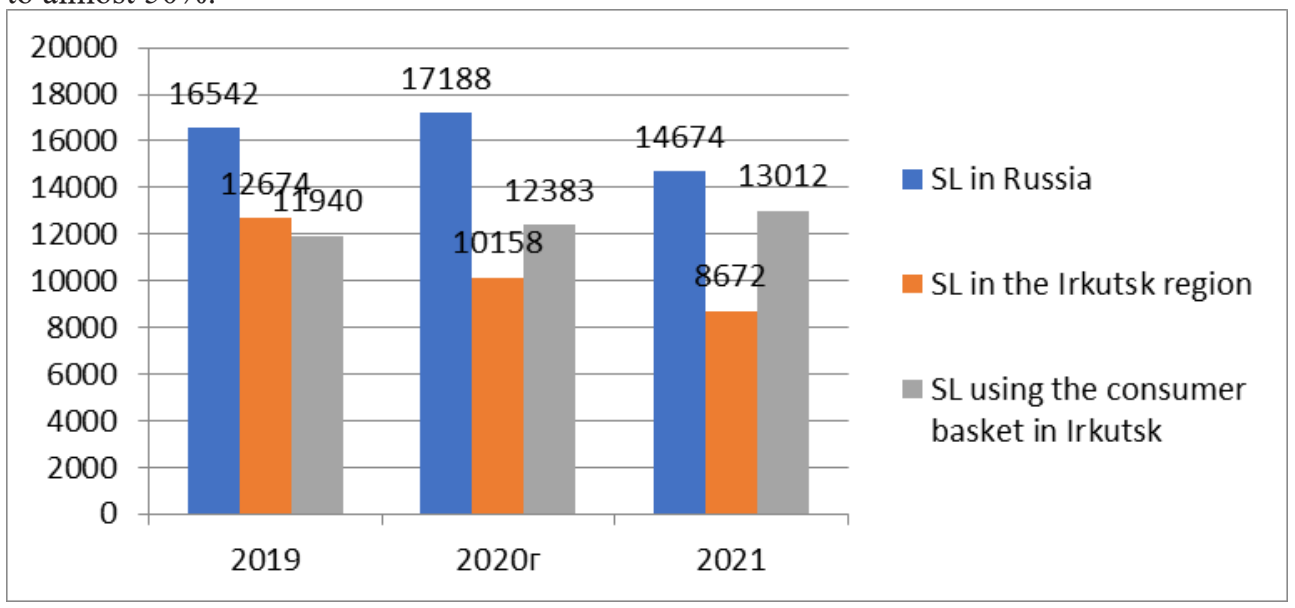

Fig. 3. Comparative change in the subsistence level on average across Russia and the Irkutsk region

As the results of the analysis show, an increase in the SL is planned for the territory of Russia as a whole, but in other parts of the regions of Russia there will be a drop in the SL, therefore, it is premature to switch to a "relative" approach to calculating the SL based on the median salary. 


\section{Conclusion}

In connection with the expected change in the methodology for calculating the subsistence level in 2021, based on the analysis carried out, it is concluded that in order to calculate the SL using the medial salary, the calculation methodology needs to be revised. The median salary on average across the entire territory of Russia is fundamentally different from the median value for the regions, e.g., in the Irkutsk region, the deviation is $40 \%$ in 2020 and 2021. Based on the above, we believe that the use of the median salary for the basis of the SL calculations in the regions is premature.

\section{References}

1. M.M. Ivanova, Rate Setting and Wages in Construction. Scientific Journal, 10 (2019)

2. A.E. Ilyin, A.V. Saprykin, Labor Economics. Scientific Journal, 4 (2017)

3. I. V. Yamschikova, I.A. Lisetskij, Analysis of costs for land development in price of construction products, MATEC Web of Conferences (2018)

4. I. V. Yamschikova, E. I. Naumov, Optimizing the cost of innovative design products, MATEC Web of Conferences (2018)

5. O.N. Antonyan, A.S. Solovieva, K.A. Strelnikova, Competitiveness in the global world: economics, science, technology, 12(59), 7 (2017)

6. P.P. Osipov, New ideas of the new century: materials of the international scientific conference of the Department of Architecture and Design, Pacific State University, 3, 459 (2020)

7. Federal Sectoral Rate Agreement on the Construction and Industry of Building Materials for 2017-2020

8. A.A. Volkova, Wages in construction industry Rate Setting and Wages in Construction, 10, 47 (2019)

9. N.M. Volovskaya, L.K. Plyusnina, A.V. Rusina, Siberian Socium, 1(1), 25 (2017)

10. D.S. Ogar, Features of wages in construction industry In the publication: Information Technology, Energy and Economics. Proceedings of the XVI International Scientific and Technical Conference of Students and Postgraduates, 3, 121 (2019) 